\title{
Solubility of Anthracene in Binary Alkane + Chlorocyclohexane and Alkane + 1-Chlorooctane Solvent Mixtures at 298.2 K
}

\author{
Carmen E. Hernández, Karen S. Coym, Lindsay E. Roy, Joyce R. Powell, Mary E. R. McHale, and \\ William E. Acree, Jr.* \\ Department of Chemistry, University of North Texas, Denton, Texas 76203-5070
}

\begin{abstract}
Experimental solubilities are reported for anthracene dissolved in seven binary alkane + chlorocyclohexane and seven binary alkane +1 -chlorooctane solvent mixtures at $25{ }^{\circ} \mathrm{C}$. The alkane cosolvents studied were hexane, heptane, octane, cyclohexane, methylcyclohexane, 2,2,4-trimethylpentane, and tertbutylcyclohexane (also called (1,1-dimethylethyl)cyclohexane). Results of these measurements are used to test two mathematical representations based upon the combined nearly ideal binary solvent (NIBS)/ Redlich-Kister and modified Wilson equations. For the 14 systems studied, both equations were found to provide an accurate mathematical representation of the experimental data, with an overall average absolute deviation between measured and calculated values being $0.5 \%$ and $0.8 \%$ for the combined NIBS/ Redlich-Kister and modified Wilson equations, respectively.
\end{abstract}

\section{Introduction}

Solid-liquid equilibrium data of organic nonelectrolyte systems are becoming increasingly important in the petroleum industry, particularly in light of present trends toward heavier feedstocks and known carcinogenicity/ mutagenicity of many of the larger polycyclic aromatic compounds. Solubility data for a number of polycyclic aromatic hydrocarbons (i.e., anthracene and pyrene) and heteroatom polynuclear aromatics (i.e., carbazole, dibenzothiophene, and xanthene) have been published in the recent chemical literature (for a listing of references, see Acree $(1994,1995 a, b))$. Despite efforts by experimentalists and scientific organizations, both in terms of new experimental measurements and critically-evaluated data compilations, there still exist numerous systems for which solubility data are not readily available.

To address this problem, researchers have turned to predictive methods as a means to generate desired quantities. Numerous equations have been suggested for predicting solute solubilities in binary solvent mixtures. For the most part, the predictive methods do provide fairly reasonable estimates for noncomplexing systems. There still remains, however, the need to develop better predictive expressions and mixing models to describe the more nonideal complexing systems believed to contain hydrogenbonding solvent components. Continued development of solution models for describing the thermodynamic properties of a solute in binary solvent systems requires that a large data base be available for assessing the applications and limitations of derived expressions. Currently, only a limited data base exists for crystalline nonelectrolyte solubility in binary solvent mixtures. For this reason, anthracene solubilities were determined in seven binary alkane + chlorocyclohexane and seven binary alkane + 1-chlorooctane solvent mixtures. Results of these measurements are used to further test the descriptive abilities of two previously derived expressions.

\section{Experimental Methods}

Anthracene (Acros, 99.9+\%) was recrystallized three times from 2-propanone. Chlorocyclohexane (Aldrich, 99\%), 1-chlorooctane (Aldrich, 99\%), hexane (Aldrich, 99+\%),

* To whom correspondence should be addressed. E-mail: acree@unt.edu.
Table 1. Experimental Mole Fraction Solubilities of Anthracene $\left(x_{\mathrm{A}}^{\text {sat }}\right)$ in Binary Alkane (B) + Chlorocyclohexane (C) Solvent Mixtures at $25.0^{\circ} \mathrm{C}$

\begin{tabular}{|c|c|c|c|}
\hline$x_{c}^{8}$ & $x_{\mathrm{A}}^{\mathrm{sat}}$ & $x \varepsilon$ & $x_{\mathrm{A}}^{\mathrm{sat}}$ \\
\hline \multicolumn{4}{|c|}{ Hexane (B) + Chlorocyclohexane (C) } \\
\hline 0.0000 & 0.001274 & 0.6173 & 0.004402 \\
\hline 0.1112 & 0.001735 & 0.8145 & 0.005450 \\
\hline 0.2203 & 0.002236 & 0.8978 & 0.005919 \\
\hline 0.4256 & 0.003355 & 1.0000 & 0.006353 \\
\hline 0.5154 & 0.003809 & & \\
\hline \multicolumn{4}{|c|}{ Heptane (B) + Chlorocyclohexane (C) } \\
\hline 0.0000 & 0.001571 & 0.6565 & 0.004688 \\
\hline 0.1331 & 0.002072 & 0.8369 & 0.005656 \\
\hline 0.2419 & 0.002543 & 0.9205 & 0.005995 \\
\hline 0.4466 & 0.003550 & 1.0000 & 0.006353 \\
\hline 0.5560 & 0.004197 & & \\
\hline \multicolumn{4}{|c|}{ Octane (B) + Chlorocyclohexane (C) } \\
\hline 0.0000 & 0.001838 & 0.6759 & 0.004881 \\
\hline 0.1498 & 0.002373 & 0.8457 & 0.005697 \\
\hline 0.2540 & 0.002825 & 0.9223 & 0.005993 \\
\hline 0.5037 & 0.003889 & 1.0000 & 0.006353 \\
\hline 0.5822 & 0.004330 & & \\
\hline \multicolumn{4}{|c|}{ Cyclohexane $(B)+$ Chlorocyclohexane $(C)$} \\
\hline 0.0000 & 0.001553 & 0.5864 & 0.004413 \\
\hline 0.1044 & 0.002029 & 0.7843 & 0.005355 \\
\hline 0.1966 & 0.002475 & 0.8797 & 0.005800 \\
\hline 0.3658 & 0.003320 & 1.0000 & 0.006353 \\
\hline 0.4713 & 0.003803 & & \\
\hline \multicolumn{4}{|c|}{ Methylcyclohexane (B) + Chlorocyclohexane (C) } \\
\hline 0.0000 & 0.001649 & 0.6302 & 0.004673 \\
\hline 0.1083 & $0.002 \quad 175$ & 0.8082 & 0.005465 \\
\hline 0.2219 & 0.002675 & 0.8832 & 0.005915 \\
\hline 0.4146 & 0.003582 & 1.0000 & 0.006353 \\
\hline 0.5062 & 0.004060 & & \\
\hline \multirow{2}{*}{\multicolumn{4}{|c|}{ 2,2,4-Trimethylpentane (B) + Chlorocyclohexane (C) }} \\
\hline & & & 0.003920 \\
\hline 0.1416 & 0.001499 & 0.8554 & 0.005185 \\
\hline 0.2708 & 0.001974 & 0.9287 & 0.005753 \\
\hline 0.4788 & 0.002951 & 1.0000 & 0.006353 \\
\hline 0.5672 & 0.003422 & & \\
\hline \multirow{2}{*}{\multicolumn{4}{|c|}{ tert-Butylcyclohexane (B) + Chlorocyclohexane (C) }} \\
\hline & & & 0.004738 \\
\hline 0.1530 & 0.002471 & 0.8522 & 0.005506 \\
\hline 0.2741 & 0.002930 & 0.9252 & 0.005878 \\
\hline & & 1.0000 & 0.006353 \\
\hline 0.5898 & 0.004373 & & \\
\hline
\end{tabular}

heptane (Aldrich, HPLC), octane (Aldrich, 99+\%, anhydrous), cyclohexane (Aldrich, HPLC), methylcyclohexane (Aldrich, 99+\%, anhydrous), 2,2,4-trimethylpentane (Aldrich, HPLC), and tert-butylcyclohexane (Aldrich, 99\%, also 
Table 2. Experimental Mole Fraction Solubilities of Anthracene $\left(x_{1}^{\text {iat }}\right)$ in Binary Alkane $(B)+1$-Chlorooctane (C) Solvent Mixtures at $25.0^{\circ} \mathrm{C}$

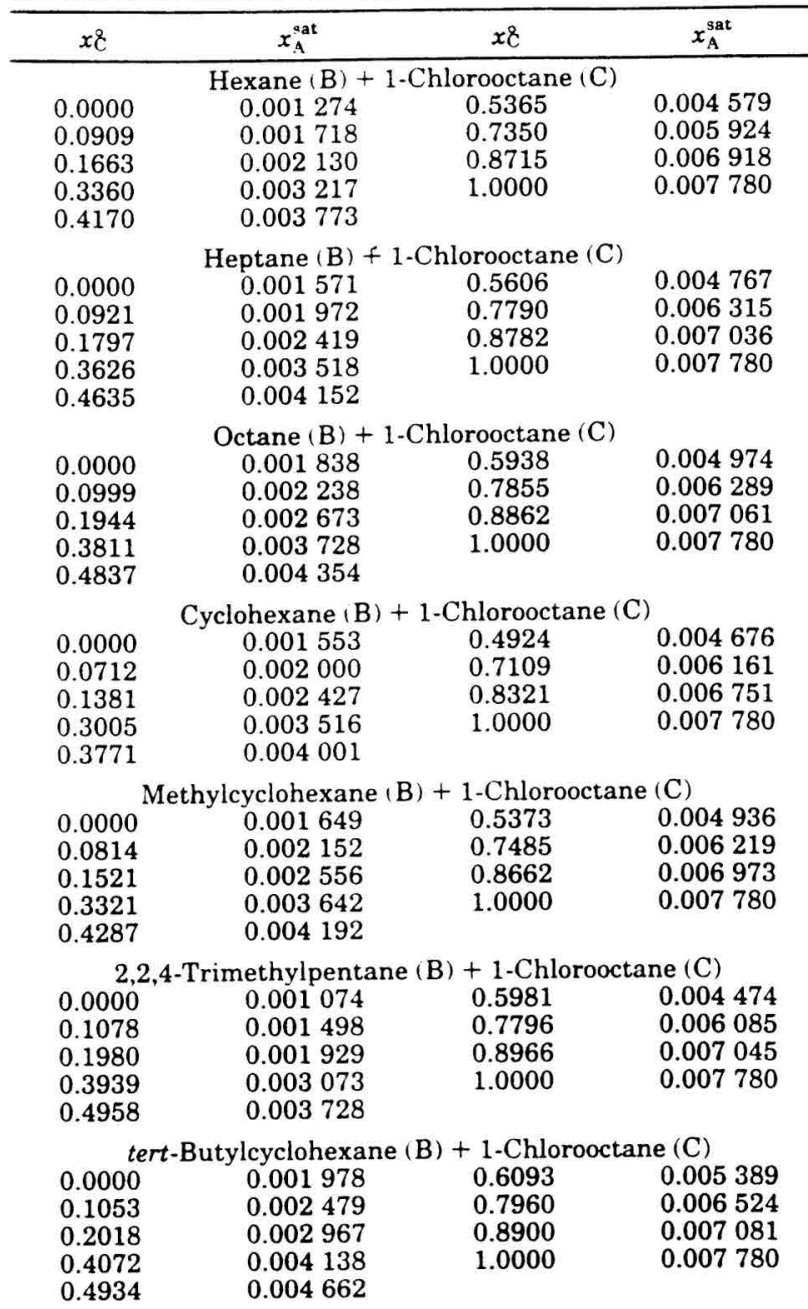

called (1,1-dimethylethyl)cyclohexane) were stored over molecular sieves and distilled shortly before use. Gas chromatographic analysis showed solvent purities to be $99.7 \mathrm{~mol} \mathrm{\%}$ or better. Binary solvent mixtures were prepared by mass so that compositions could be calculated to 0.0001 mole fraction.

Excess solute and solvent were placed in amber glass bottles and allowed to equilibrate in a constant temperature water bath at $(25.0 \pm 0.1)^{\circ} \mathrm{C}$ with periodic agitation for at least 3 days (often longer). Attainment of equilibrium was verified both by repetitive measurements after a minimum of 3 additional days and by approaching equilibrium from supersaturation by preequilibrating the solutions at a higher temperature. Aliquots of saturated anthracene solutions were transferred through a coarse filter into a tared volumetric flask to determine the amount of sample and diluted quantitatively with methanol for spectrophotometric analysis at $356 \mathrm{~nm}$ on a Bausch and Lomb Spectronic 2000. Concentrations of the dilute solutions were determined from a Beer-Lambert law absorbance versus concentration working curve derived from measured absorbances of standard solutions of known molar concentration. Apparent molar absorptivities of the nine standard solutions varied systematically with molar concentration and ranged from approximately $\epsilon /\left(\mathrm{L} \mathrm{mol}^{-1}\right.$ $\left.\mathrm{cm}^{-1}\right)=7450$ to $\epsilon /\left(\mathrm{L} \mathrm{mol}^{-1} \mathrm{~cm}^{-1}\right)=7150$ for anthracene concentrations ranging from $C /\left(\mathrm{mol} \mathrm{L}^{-1}\right)=6.75 \times 10^{-5}$ to $C /\left(\mathrm{mol} \mathrm{L}^{-1}\right)=2.25 \times 10^{-4}$. Identical molar absorptivities
Table 3. Mathematical Representation of Anthracene Solubilities in Several Binary Alkane (B) + Chloroalkane (C) Solvent Mixtures

\begin{tabular}{|c|c|c|c|c|}
\hline \multirow[b]{2}{*}{$\begin{array}{l}\text { binary solvent system } \\
\text { component (B) + component (C) }\end{array}$} & \multicolumn{2}{|c|}{ eq 1} & \multicolumn{2}{|c|}{ eq 2} \\
\hline & $S_{1}^{a}$ & $\begin{array}{c}\% \\
\operatorname{dev}^{b}\end{array}$ & $\Lambda_{i j}^{\text {adj c }}$ & $\begin{array}{c}\% \\
\text { dev. }\end{array}$ \\
\hline hexane + chlorocyciohexane & $\begin{array}{l}1.098 \\
0.209 \\
0.085\end{array}$ & 0.6 & $\begin{array}{l}2.043 \\
0.506\end{array}$ & 1.1 \\
\hline heptane + chlorocyclohexane & 0.796 & 0.4 & $\begin{array}{l}1.724 \\
0.564\end{array}$ & 1.6 \\
\hline octane + chlorocyclohexane & 0.571 & 0.8 & $\begin{array}{l}1.579 \\
0.651\end{array}$ & 1.3 \\
\hline cyciohexane + chlorocyclohexane & $\begin{array}{l}0.940 \\
0.346 \\
0.119\end{array}$ & 0.3 & $\begin{array}{l}2.188 \\
0.564\end{array}$ & 0.2 \\
\hline $\begin{array}{l}\text { methylcyciohexane }+ \\
\text { chlorocyclohexane }\end{array}$ & $\begin{array}{l}0.841 \\
0.327 \\
0.353\end{array}$ & 0.8 & $\begin{array}{l}1.869 \\
0.477\end{array}$ & 1.0 \\
\hline $\begin{array}{l}\text { 2,2,4-trimethylpentane }+ \\
\text { chlorocyclohexane }\end{array}$ & $\begin{array}{r}0.626 \\
0.146 \\
-0.133\end{array}$ & 0.2 & $\begin{array}{l}1.376 \\
0.680\end{array}$ & 0.8 \\
\hline $\begin{array}{l}\text { tert-butylcyclohexane }+ \\
\text { chlorocyclohexane }\end{array}$ & $\begin{array}{r}0.402 \\
0.075 \\
-0.263\end{array}$ & 0.5 & $\begin{array}{l}1.521 \\
0.854\end{array}$ & 0.9 \\
\hline hexane +1 -chlorooctane & $\begin{array}{l}1.287 \\
0.397\end{array}$ & 0.3 & $\begin{array}{l}2.159 \\
0.506\end{array}$ & 0.6 \\
\hline heptane + 1-chlorooctane & 0.918 & 0.8 & $\begin{array}{l}1.782 \\
0.564\end{array}$ & 0.9 \\
\hline octane +1 -chlorooctane & 0.618 & 0.7 & $\begin{array}{l}1.579 \\
0.651\end{array}$ & 0.9 \\
\hline cyclohexane + 1-chlorooctane & $\begin{array}{l}1.265 \\
0.657 \\
0.320\end{array}$ & 0.6 & $\begin{array}{l}1.898 \\
0.332\end{array}$ & 0.6 \\
\hline $\begin{array}{l}\text { methylcyclohexane }+ \\
1 \text {-chlorooctane }\end{array}$ & $\begin{array}{l}1.034 \\
0.553 \\
0.446\end{array}$ & 0.7 & $\begin{array}{l}1.376 \\
0.303\end{array}$ & 0.5 \\
\hline $\begin{array}{l}\text { 2,2,4-trimethylpentane }+ \\
\text { 1-chlorooctane }\end{array}$ & $\begin{array}{l}1.065 \\
0.083 \\
0.220\end{array}$ & 0.5 & $\begin{array}{l}1.753 \\
0.593\end{array}$ & 1.1 \\
\hline $\begin{array}{l}\text { tert-butylcyclohexane }+ \\
\text { 1-chlorooctane }\end{array}$ & $\begin{array}{l}0.721 \\
0.165\end{array}$ & 0.2 & $\begin{array}{l}1.724 \\
0.593\end{array}$ & 0.3 \\
\hline
\end{tabular}

a Combined NIBS/Redlich-Kister curve-fit parameters are ordered as $S_{0}, S_{1}$, and $S_{2} .{ }^{b}$ Deviation $(\%)=(100 / 7) \sum \mid\left[\left(x_{A}^{\text {sat }}\right)^{\text {calc }}-(\right.$ $\left.x_{\mathrm{A}}^{\text {sat }}\right)^{\exp } V\left(x_{\mathrm{A}}^{\text {sat }}\right) \exp \mid{ }^{c}$ Adjustable parameters for the modified Wilson equation are ordered as $\Lambda_{\mathrm{BC}}^{\mathrm{adj}}$ and $\Lambda_{\mathrm{CB}}^{\mathrm{adj}}$.

were obtained for select anthracene standard solutions that contained up to $5 \mathrm{vol} \%$ of the neat alkane and chloroalkane cosolvents. Experimental anthracene solubilities in the seven binary alkane + chlorocyclohexane and seven binary alkane +1 -chlorooctane solvent mixtures are listed in Tables 1 and 2, respectively. Numerical values represent the average of between four and eight independent determinations, with the measured values being reproducible to within $\pm 1.8 \%$.

\section{Results and Discussion}

Acree and co-workers (Acree and Zvaigzne, 1991) suggested possible mathematical representations for isothermal solubility data based upon either a combined NIBS/ Redlich-Kister model

$$
\ln x_{\mathrm{A}}^{\mathrm{sat}}=x_{\mathrm{B}}^{\circ} \ln \left(x_{\mathrm{A}}^{\mathrm{sat}}\right)_{\mathrm{B}}+x_{\mathrm{C}}^{\circ} \ln \left(x_{\mathrm{A}}^{\mathrm{sat}}\right)_{\mathrm{C}}+x_{\mathrm{B}}^{\circ} x_{\mathrm{C}}^{\circ} \sum_{i=0}^{N} S_{i}\left(x_{\mathrm{B}}^{\circ}-x_{\mathrm{C}}^{\circ}\right)^{i}
$$

or modified Wilson equation

$$
\begin{aligned}
& \ln \left[a_{\mathrm{A}}(\mathrm{s}) / x_{\mathrm{A}}^{\mathrm{sat}}\right]=1-x_{\mathrm{B}}^{\circ}\left\{1-\ln \left[a_{\mathrm{A}}(s) /\left(x_{\mathrm{A}}^{\mathrm{sat}}\right)_{\mathrm{B}}\right]\right\} /\left(x_{\mathrm{B}}^{\circ}+\right. \\
&\left.x_{\mathrm{C}}^{\circ} \Lambda_{\mathrm{BC}}^{\mathrm{adj}}\right)-x_{\mathrm{C}}^{\circ}\left\{1-\ln \left[a_{\mathrm{A}}(s) /\left(x_{\mathrm{A}}^{\mathrm{sat}}\right)_{\mathrm{C}}\right]\right\} /\left(x_{\mathrm{B}}^{\circ} \Lambda_{\mathrm{CB}}^{\mathrm{adj}}+x_{\mathrm{C}}^{\circ}\right)
\end{aligned}
$$


where the various $S_{i}$ and $\Lambda_{i j}^{\text {adj }}$ "curve-fit" parameters can be evaluated via least-squares analysis. In eqs 1 and $2 x_{\mathrm{B}}^{\circ}$ and $x_{C}^{\circ}$ refer to the initial mole fraction composition of the binary solvent calculated as if solute $\mathrm{A}$ were not present, $a_{\mathrm{A}}(s)$ is the activity of the solid solute, $N$ is the number of curve-fit parameters used, and $\left(x_{\mathrm{A}}^{\mathrm{sat}}\right)_{i}$ is the saturated mole fraction solubility of the solute in pure solvent $i$. The numerical value of $a_{A}(s)$ used in the modified Wilson computations was $a_{\mathrm{A}}(s)=0.00984$ (Powell et al., 1997).

The ability of eqs 1 and 2 to mathematically represent the experimental solubility of anthracene in the 14 binary alkane + chloroalkane solvent systems is summarized in Table 3 in the form of "curve-fit" parameters and percent deviations in back-calculated solubilities. Each percent deviation is based upon the measured anthracene solubility data at the seven different binary solvent compostions. Careful examination of Table 3 reveals that both equations provide an accurate mathematical representation for how the solubility of anthracene varies with solvent composition. For the 14 anthracene systems studied, the overall average absolute deviation between the experimental and calculated values is $0.5 \%$ and $0.8 \%$ for eqs 1 and 2 , respectively, which is less than the experimental uncertainty.

\section{Literature Cited}

Acree. W. E., Jr. Polycyclic Aromatic Hydrocarbons in Pure and Binary Solvents; IUPAC Solubility Data Series 54; Oxford University Press: Oxford, U.K., 1994.

Acree, W. E., Jr. Polycyclic Aromatic Hydrocarbons: Binary Nonaque. ous Systems: Part 1 (Solutes $A-E$ ); IUPAC Solubility Data Series 58; Oxford University Press: Oxford, U.K., 1995a.

Acree, W. E., Jr. Polycyclic Aromatic Hydrocarbons: Binary Nonaqueous Systems: Part 2 (Solutes F-Z); IUPAC Solubility Data Series 59; Oxford University Press: Oxford, U.K., 1995b.

Acree, W. E., Jr.; Zvaigzne, A. I. Thermodynamic Properties of Nonelectrolyte Solutions. Part 4. Estimation and Mathematical Representation of Solute Activity Coefficients and Solubilities in Binary Solvents Using the NIBS and Modified Wilson Equations. Thermochim. Acta 1991, 178, 151-167.

Powell, J. R.; Coym, K. S.; Acree, W. E., Jr. Solubility of Anthracene in Binary Alcohol + 2-Methoxyethyl Ether Solvent Mixtures. $J$. Chem. Eng. Data 1997, 42, 395-397.

Received for review April 22, 1997. Accepted June 9, 1997 ${ }^{\otimes}$ C.H thanks the University of North Texas and the U.S. Department of Education for support provided under the Ronald E. McNair Postbaccalaureate Achievement Program. J.P. thanks the American Association of University Women (AAUW) for a dissertation fellowship.

JE970100T

Abstract published in Advance ACS Abstracts, July 15, 1997. 